\title{
Comparing hydraulic and electromechanical drives by electric motor's power
}

\author{
Otto Grigorov ${ }^{1 *}$, Galyna Anishchenko ${ }^{1}$, Evhen Druzhynin ${ }^{1}$, Vsevolod Strizhak ${ }^{1}$, Mariana Strizhak ${ }^{1}$, and Volodymyr \\ Malashchenko ${ }^{2}$ \\ ${ }^{1}$ National Technical University "Kharkiv Polytechnic Institute", 61000 Kharkiv, Ukraine \\ ${ }^{2}$ National University "Lviv Polytechnic ", 79000 Lviv, Ukraine
}

\begin{abstract}
The authors have made the analysis of energy consumption by positive-displacement hydraulic drive and asynchronous motor with phase rotor in the course of crane mechanisms operation at all stages of motion: acceleration, movement at nominal or intermediate speed, and deceleration. There have been determined and compared equivalent capacities per work cycle for electric and hydraulic drives of crane mechanisms depending on operating conditions group and operation time. There has been justified the decrease of rated capacity of electric motor of crane mechanisms' hydraulic drive as compared with the case of applying asynchronous motor with phased rotor for the same mechanisms.
\end{abstract}

\section{Introduction}

The price of a hydraulic drive's electric motor, with other conditions considered, is determined by its capacity, which in the long run affects capital expenditure on hoisting machine $[1,3-6]$. That is why it is reasonable not also to determine electric drive's capacity, but also to compare it with that of electromechanical drive [2].

\section{Scientific novelty}

The scientific novelty of this work lies in the fact that for the first time an analytical expression was obtained to determine the equivalent power of the electric motor drive, taking into account the linear change in time of the power that is consumed by the engine during acceleration and generator braking. The validity of the obtained expressions was confirmed by tests on real bridge cranes of the Kharkov "Turboatom" factory with a lifting capacity of $30 / 5$ tons, as well as on a bridge crane of the "Uzlovsky" machine-building factory with a lifting capacity of 15/3 tons and on the "Kirovets" framecrane with a lifting capacity of 10 tons installed in the Kiev port.

\section{Practical significance}

The practical significance of this study lies in the fact that during field experiments on the bench (fig. 1), as well as on the above-mentioned real cranes, it was possible to reduce the equivalent power of the drive motor by $1.4 \div$ 1.6 times for any groups of operating modes of the movement (rotation) mechanism of the crane. So, for example, it was possible to reduce the power of the mechanism for moving the bridge crane with a lifting capacity of $15 / 3$ tons at the "Uzlovsky" machine-building factory from $11 \mathrm{~kW}$ to $7 \mathrm{~kW}$, and the turning mechanism of the hydrostatic drive of the "Kirovets" frame-crane with a lifting capacity of 10 tons from $55 \mathrm{~kW}$ to $40 \mathrm{~kW}$. Note that in addition to reducing the equivalent power, there is a decrease in the cost of electricity for the completion of the crane operation cycle [7]. From the graphs given in [7] it is clearly seen that the ratio of energy costs in an electromechanical drive in relation to energy costs in an adjustable hydraulic actuator lies in the range from 1.5 to 3.1 in the absence of uniform crane movement. This ratio reaches 1 at such values of the time of uniform movement of the crane (from 28 to 75 seconds), which are not found in real operating conditions of the crane. The above data follows from the diagram of changes in power consumption of two compared drives (7, fig. 2). A decrease in dynamic loads on the metal structures of the crane by about $40 \%$ was also noted [8], [9].

\section{Aim and problem statement}

The aim of this work is to substantiate the decrease of rating capacity of drive electric motor in crane mechanisms' hydraulic drives as compared with the case of using asynchronous motor with phase rotor for the same mechanisms. To achieve the set aim it is necessary to solve a number of tasks: to analyze the character of power consumption by hydrostatic power drive and asynchronous motor with phase rotor in the course of operation of crane mechanisms at all stages of motion: acceleration, movement at nominal or intermediate speed, deceleration; to determine equivalent capacities of both types of power drives and to compare them.

Corresponding author: ottow@kpi.kharkov.ua 


\section{Results}

The comparative analysis has been performed on the results of industrial testing of two types of drives of motion mechanisms for overhead cranes with hoisting capacity of $30 / 5,20 / 5,15 / 3$ tons, swing-out mechanism of frame-crane with hoisting capacity of 10 tons and benchmark tests (fig. 1).

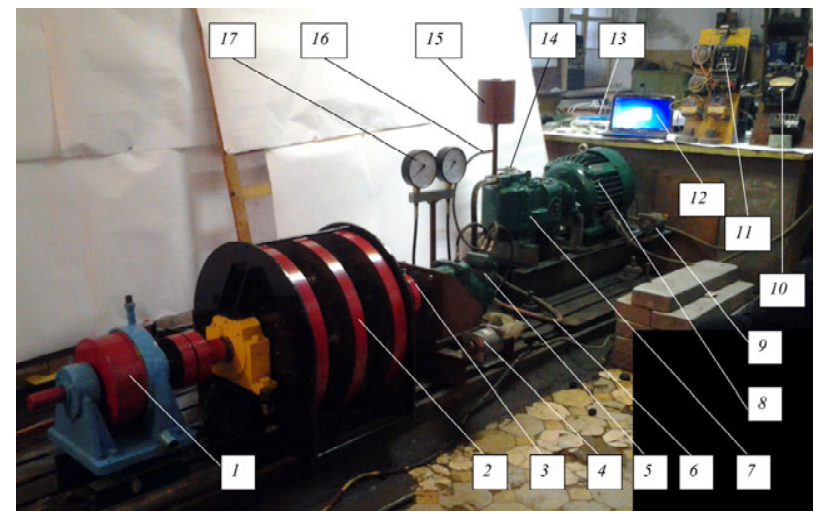

Fig. 1. The bench for testing movement and swing mechanisms of cranes with positive displacement regulated hydraulic drive: 1 - Weight cooled with running water to imitate static momentum of resistance to movement or swing; 2 - Flywheel weights to imitate the momentum of rotating masses energy (parameters of a wide range of hoisting capacity cranes are imitated); 3 - Radio strain sensors to transmit the twisting momentum to the amplifier and on to ADC; $4-\mathrm{TMG}-30 \mathrm{P}$ tacho-generator for recording hydromotor's rotation speed; 5 IIM\#5 hydromotor; 6 - High pressure pipes; 7 - IID\#5 axialpiston pump; 8 - AO 62-4 electric motor; 9 - TMG-30P tachogenerator for recording rotation speed of electric motor as well as its operation in generation mode; 10 - Dial wattmeter; 11 -

P004 power converter; 12 - Laptop; 13 - Amplifiers; 14 -

Executive part of the control system; 15 - Refilling tank; 16 Outlet pipe; 17 - Pressure gauges

The analysis shows that at uniform acceleration and deceleration there appear a number of discrepancies in the manner of drives parameters changes (fig. 2).
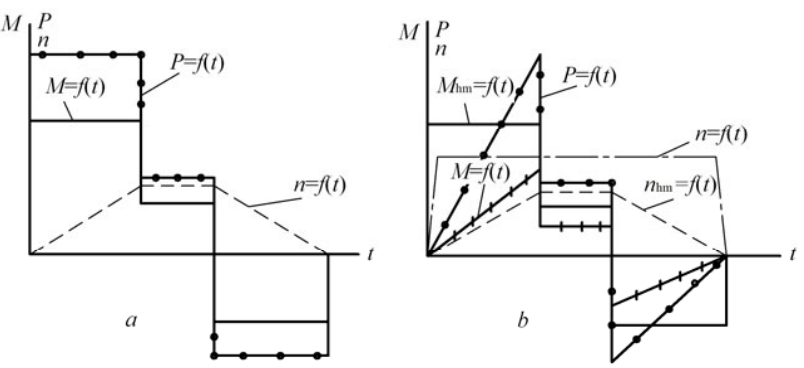

Fig. 2. Diagrams of changes in drives' parameters

$\mathrm{a}$ - electrical; $\mathrm{b}$ - hydraulic; $\mathrm{M}, \mathrm{P}$ - rotation torque and power on the shaft of electric motor; $n, n_{h m}-$ the rates of electric motor and hydromotor's rotation; $\mathrm{M}_{\mathrm{hm}}$ - the momentum on the hydromotor's shaft; $\mathrm{t}$ - time.

Rotating torque on the rotor of hydraulic drive's electric motor, and thus the current spent on the motor's heating-up change in accordance with the linear law (proportionally to the speed of the crane's movement). Concerning a common electric drive (asynchronous electric motor with phase rotor) this value remains practically unchanged. Due to this fact, the thermal conditions within the hydraulic drive's motor are less intense, which permits in a number of cases to decrease the rated capacity of driving electric motors. Thus, it became possible to use a 7 kilowatt motor for hydraulic drive of a bridge-crane with hoisting capacity of $15 / 3$ tons instead of an $11 \mathrm{~kW}$ motor, for the hydraulic swing drive of "Kirovets" frame-crane with hoisting capacity of 10 tons a $40 \mathrm{~kW}$ motor was used instead of $55 \mathrm{~kW}$ motor with the same time on starting-and-braking processes.

It is reasonable to compare the powers of electric motors of two different types of drives when used in various operation conditions. The numerical values are given for the bridge-crane with hoisting capacity of $30 / 5$ tons (the span is $22.5 \mathrm{~m}$; the total weight without cargo is 43.3 tons; the carriage weight is 10.632 tons; the rated motion speed is 76.5 $\mathrm{m}$ per minute; the rollers' diameter is $800 \mathrm{~mm}$; the crane's motion mechanism's drive is separate).

The hydraulic drive for such a crane consists of asynchronous motors of A0 or A02 series, IID regulated pumps, IIM hydromotors, electronic tracking system to control pumps' effectiveness; electric drive includes metallurgical crane motors of MTV series. Hydraulic drive's electric motor is cut off from power during the breaks between the cycles of the motion mechanism's operation, there being no need in its constant operation.

The research were conducted in the operation conditions of both types of drives with operation periods (OP) of 15, 25, 40, 60\% (groups of operation conditions of $\mathrm{M} 1 \div \mathrm{M} 8$ correspondingly) for operation conditions of high and low intensity of transition processes, for two options of electric drive motor's deceleration - by means of opposition circuiting and mechanical brake for different cases of using drives at low speeds of movement ( $\left.e=V / V_{\text {rated }}\right)$.

By transition process of high intensity are meant the operation conditions ensuring crane acceleration of $a_{\mathrm{cc}}=0,21 \mathrm{~m} / \mathrm{s}^{2}$, crane deceleration $a_{\mathrm{dec}}=0,41 \mathrm{~m} / \mathrm{s}^{2}$; at low intensity dimensions, and some other parameters.

By analyzing the curves in Fig. 4, the following conclusions can $a_{\mathrm{acc}}=a_{\mathrm{dec}}=0,1 \mathrm{~m} / \mathrm{s}^{2}$. The high intensity operation conditions are ensured at the operation of the hydromotor and the pump under pressure of $160 \mathrm{MPa}$ which is limited by safety valves adjustment. The low intensity operation conditions are stipulated by electric drive at controller's smooth switching from the zero position to the limit and back.

Considering the operation of a crane's motion and swinging mechanisms in the modes of acceleration, even motion, and deceleration, it is reasonable to select the drive electric motor's capacity by equivalent capacity $P_{e}$ per cycle:

$$
P_{e}=\sqrt{\frac{\int_{0}^{t} P^{2} d t}{t}}
$$

where $P_{\mathrm{e}}-$ current power on the shaft of electric motor; $t$ - time. 
The research has shown that in transition processes at the linear change in the pump adjustment parameter the power and torque momentum on the electric motor shaft, as well as consumed and recuperated power and the current in stator windings change linearly. That is why, as to an electrical hydraulic drive with taking into account its operation by trapeziform tachogram the expression (1) can be presented as follows:

$$
P_{\mathrm{e}}=\sqrt{\frac{\frac{1}{3} P_{\mathrm{p} . \max }^{2} \frac{1}{\eta_{\mathrm{red}}^{2} \eta_{\mathrm{h} . \text { drive }}^{2}} t_{p}+P_{\mathrm{p} . \mathrm{x}}^{2} \frac{1}{\eta_{\text {red }}^{2} \eta_{\mathrm{h} . \text { drive }}^{2}} t_{\mathrm{p} . \mathrm{x}}+\frac{1}{3} P_{\mathrm{g} . \mathrm{max}}^{2} \eta_{\mathrm{red}}^{2} \eta_{\mathrm{h} . \text { drive }}^{2} \eta_{\mathrm{el} . \text { en. } \mathrm{g} . \mathrm{t} . \mathrm{t}}^{4}}{t_{\mathrm{p}}+t_{\mathrm{p} . \mathrm{x}}+t_{\mathrm{h} . \mathrm{t}}+\frac{1}{3} \theta}}
$$

where $P_{\mathrm{p} \text { max }}-$ maximum positive power on the flywheel shaft at the end of the acceleration period; $P_{\mathrm{p} . \mathrm{x}}$ - positive power on the flywheel shaft at even motion; $P_{\text {g.max }}-$ maximum negative power on the flywheel shaft at the initial period of generative deceleration; $\eta_{\text {red }}-$ reducer's efficiency factor at the end of acceleration period, at the beginning of generative deceleration, at even motion; $\eta_{\text {h.drive }}$ - total efficiency factor of the hydrostatic drive at the end of acceleration period, at the beginning of generative deceleration, at even motion; $\eta_{\text {el.en.g }}-$ electric motor's efficiency factor in generative mode of operation.

Time $t_{\mathrm{p}}$ of acceleration and $t_{\mathrm{h} . \mathrm{t}}$ of deceleration is written without 0.75 coefficient which is introduced for taking into account the worsening of the motor's cooling conditions in common electric drives in transition periods, because in hydraulic drives electric motor rotates in transition periods at about rated speed with no worsening of cooling conditions.

The $1 / 3$ coefficient in front of $\theta$ shows that the motor's cooling conditions worsen when it is cut off from power supply.

The $\eta_{\text {el.en.g }}^{4}$ multiplier shows that the mechanical power of motor working as generator at the same electrical power conditioning its heating is $1 / \eta_{\text {el.en.g }}^{2}$ times more than the motor's mechanical power at its operation in the motion mode [3]. For electric drive at accelerating and decelerating with constant rotation torques on the motor's shaft the expression (1) can be written as follows:

$$
P_{\mathrm{e}}=\sqrt{\frac{P_{\mathrm{p} . \max }^{2} \frac{1}{\eta_{\mathrm{red}}^{2}} t_{\mathrm{p}}+P_{\mathrm{p} . \mathrm{x}}^{2} \frac{1}{\eta_{\mathrm{red}}^{2}}+P_{\mathrm{g} . \max }^{2} \eta_{\mathrm{red}}^{2} \frac{\eta_{n}^{2}}{\eta_{\sigma}^{2}} t_{\mathrm{t} . \mathrm{d}}}{0,75\left(t_{\mathrm{p}}+t_{\mathrm{m}}\right)+t_{\mathrm{p} . \mathrm{x}}+\frac{1}{3} \theta}}
$$

where $P_{\text {p.max }}$ - maximum negative power on the flywheel shaft at the initial period of its operation on countercurrent; $t_{\text {t.d }}$ - time of drive's deceleration while operating on countercurrent; $\eta_{\text {п }}-$ a drive's efficiency factor while operating on countercurrent; $\eta_{\sigma}$ - efficiency factor of motor's stator while operating on countercurrent.

Expression (3) was obtained bearing in mind that during the motor's accelerating and its operating on countercurrent under the integral sign in formula (1) there is indicated the power attributed to the crane's rated speed [3].

Thus, concerning a crane's electric drive, the power on the electric motor's shaft is taken as constant for convenience not only on the even movement stage, but also remains unchanged on the whole stage of accelerating $\left(P_{\text {p.max }}\right)$ and decelerating by opposition circuiting $\left(P_{\text {g.max }}\right)$.

The motors were selected by equivalent capacity $P_{\mathrm{e}}$ per cycle, tested for overload capacity and tolerable number of activations per hour, after which the rated power was determined by the largest of the needed capacities. The results of calculations for acceleration and decelerations of various intensities, as well as for different types of electric drive's deceleration are shown in fig. 3 .

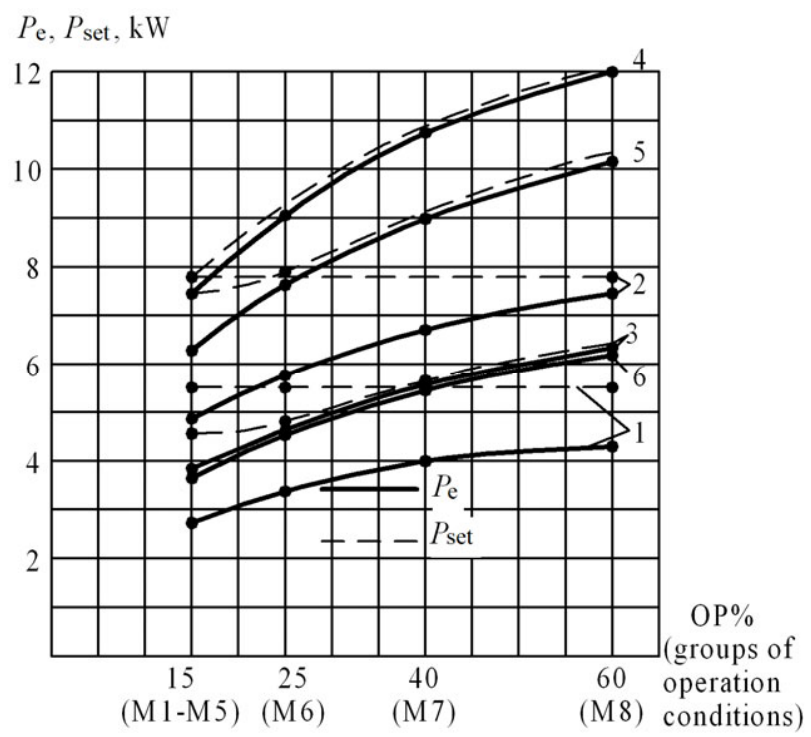

Fig. 3. Comparative graphs of rated and equivalent capacities and their relations for electric and hydraulic drives depending on the mechanism's operation time $\mathrm{OP} \%$ :

$P_{\mathrm{e}}, P_{\mathrm{e}}=f(\mathrm{OP} \%): 1,2-$ low and high (correspondingly) intensity of hydraulic drives' acceleration and deceleration; 3 , 4 - electric drive, low and high (correspondently) intensity of acceleration and deceleration, decelerating by countercurrent; 5, 6 - electric drive, low and high (correspondently) intensity of acceleration and deceleration, decelerating by a mechanical brake.

Analyzing the graphs, the following conclusions can be made. In the same operation conditions equivalent capacity of hydraulic drive per working cycle of electric 
motor is less than that of electric drive which can be explained by favourable conditions of electric drive's load (electric motor initially accelerates idly, becoming loaded later) and by the absence of countercurrent deceleration. For electric drive the motor's rated capacity in the studied cases is determined by heating conditions (curves $P_{\mathrm{e}}$ and $P_{\text {set }}$ coincide), i.e. by the value of $P$. This capacity grows with the intensity of drive's operation in terms of operation period $\mathrm{OP} \%$.

The hydraulic drive motor's rated capacity in the studied cases is determined, unlike that for electric drive, by overload capacity of motors of A0 and A02 series (lines $P_{\text {set }}$ for all OP\% are located above $P_{e}$ curves) and are not determined by $\mathrm{OP} \%$ (lines 1 and 2 run parallel to $\mathrm{OP} \%$ axis [marked as OP\% in fig. 3].

In the studied cases at low intensity of acceleration and deceleration the presence or absence of countercurrent decelerating does not affect the value of the electric drive's rated capacity (curves 3 and 6 coincide); at high intensity of acceleration and deceleration the use of only mechanical brake leads to the decrease in rated capacity by $15 \%$.

In Fig. 4 there are shown the graphs built on the data of Fig. 3 with some addenda. Here, the adopted symbols $P_{\text {set.el }}, \mathrm{OP} \%$ - rated capacity of electric drive's motor taken at $\mathrm{OP} \%$ the drive is working at; $P_{\text {set.el }}=25 \%$ - the rated capacity of electric drive's motor is given for the $\mathrm{OP}=25 \%$. The ratio $P_{\text {set.el }} / P_{\text {set.h }}, \mathrm{OP}=25 \%$ gives the idea of not only of the capacities ratio, but also to some extent of mass, be made. For a hydraulic drive the best ratio of rated capacities is obtained at high intensity of acceleration and deceleration, and intensive exploiting by $\mathrm{OP} \%$ (curves $3,4,8,10$ ). In this case the ratio of $P_{\text {set.el }} / P_{\text {set.h }}$ may reach as much as 2.5 . The worst ratio of rated capacities for a hydraulic drive is noted at low intensity of acceleration and deceleration with decelerating by mechanical brake of electric drive and light intensity of operation by OP\% (curves $1,2,9$ ).

This can be explained by the fact that in these operation conditions the choice of the hydraulic drive's rated capacity is to a great extent stipulated by overload capacity of industrial motors which is 1.3 to 1.5 times less than those for metallurgy cranage.

Correlation by equivalent capacity demonstrates that the ratio of $P_{\text {set.el }} / P_{\text {set.h }}$ practically doesn't depend on $\mathrm{OP} \%$, and is always to the advantage of hydraulic drive, varying between $1.3 \ldots 1.65$ (curves $5,6,7$ ) depending on the transition processes' intensity and the type of electric drive's decelerating.

In the practice of lifting-and-shifting machines exploitation there are cases when a drive designated for operation at a predetermined rated speed $V_{\text {rated }}$ is used at the speed other than the rated speed $\left(V<V_{\text {rated }}\right)$, for instance at an insufficient distance between bridgecranes within the same span, or a small turning angle of a portal crane.

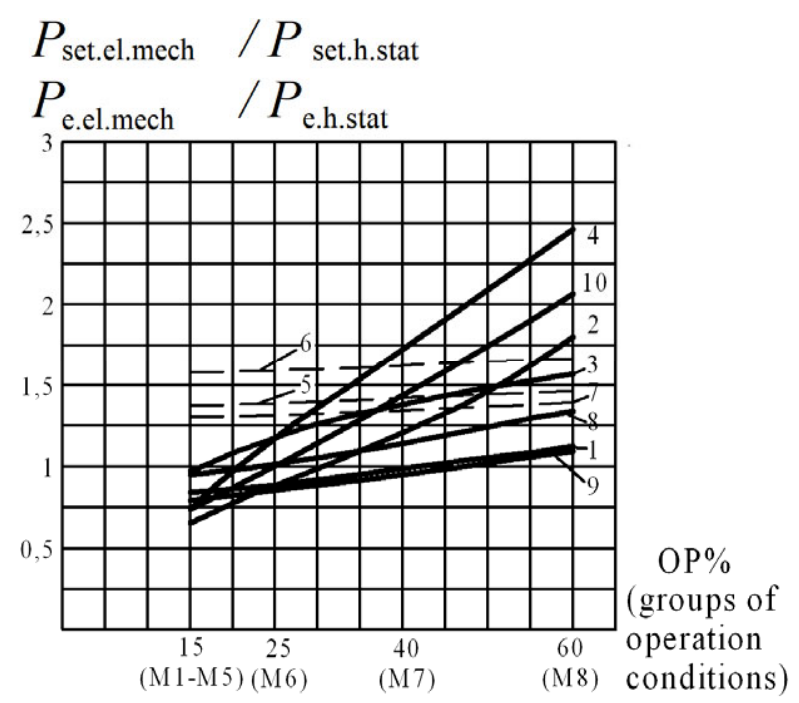

Fig. 4. Graphs of rated and equivalent capacities and their ratios for electric and hydraulic drives depending on the mechanism's operation period OP\% (groups of operation modes):

1, $2-P_{\text {set.el }}, \mathrm{OP} \%$ [marked as $\mathrm{OP} \%$ in the Figure 4] ( $P_{\text {set.h }}$; $P_{\text {set.el }} \mathrm{OP}=25 \% \quad P_{\text {set.h }}-$ at low intensity of acceleration and deceleration; 3, 4- $P_{\text {set.el }}, \mathrm{OP} \%$ ( $P_{\text {set.h }} ; P_{\text {set.el }} \mathrm{OP}=25 \% P_{\text {set.h }}-$ at high intensity of acceleration and deceleration; 5, 6- $P_{\text {e.el }} /$ $P_{\text {e.h }}-$ at low intensity of acceleration and deceleration; 7, $8-$ $\left(P_{\text {e.el }} / P_{\text {e.h }} ; P_{\text {set.el }}, \mathrm{OP} \%\right) P_{\text {set.h }}-$ at high intensity of acceleration and deceleration, electric drive's decelerating by mechanical brake; 9, $10-P_{\text {set.el }}, \mathrm{OP} \%\left(P_{\text {set.h }} ; P_{\text {set.el }}, \mathrm{OP} \%\right)$ $P_{\text {set.h }}-$ at low and high (correspondingly) intensity of acceleration and deceleration, electric drive's decelerating by mechanical brake.

In Fig.5 there is the dependency $P_{\text {e.el }}, P_{\text {e.h }}=f(e)$. The analysis of the curves demonstrates that the electric drive's equivalent capacity is the more the less its velocity capacity is used (the less e is). The hydraulic drive's equivalent capacity is the more the more its velocity capacity is used.

The analysis of the curves demonstrated in Fig.6 makes it possible to come to the following conclusions. For a hydraulic drive the best relation of equivalent capacities is achieved at insignificant use of the drives' speed capacities $(e \rightarrow 0)$. This relation is the higher, the higher intensity of transition processes is, and the higher the intensity of operation conditions by $\mathrm{OP} \%$. Thus, for example, at $e=0.0333$ the ratio $P_{\text {e.el }} / P_{\text {e.h }} \approx 22$. The worse ratio of equivalent capacities for a hydraulic drive is viewed at the maximum use of drives' speed capacities $(e=1)$. In such a case at various operation conditions the ratio $P_{\text {e.el }} / P_{\text {e.h }}$ reaches $1.3 \ldots 1.65$ which was seen earlier at the studying of curves 5, 6, 7 in Fig.4 assuming $e=1$. 


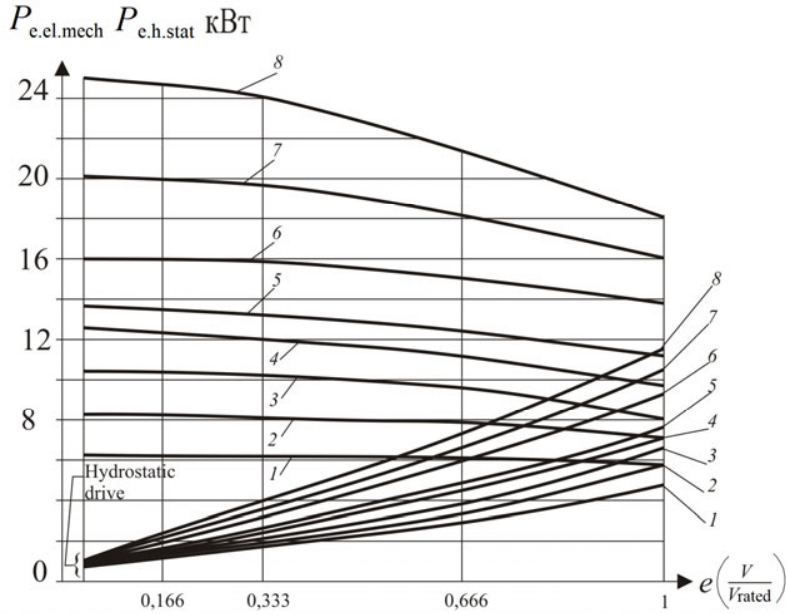

Fig. 5. The graphs of equivalent capacities $P_{\text {e.el }}, P_{\text {e.h }}=f(e)$ for electromechanical and hydraulic drives depending on their use by speed: 1 - small intensity of acceleration and deceleration, operation at $\mathrm{OP}=15 \% ; 2$ - the same at $\mathrm{OP}=25 \%$; 3 - the same at $\mathrm{OP}=40 \% ; 4$ - the same at $\mathrm{OP}=60 \% ; 5$ - high intensity of acceleration and deceleration, operation at $\mathrm{OP}=15 \% ; 6$ - the same at $\mathrm{OP}=25 \% ; 7$ - the same at $\mathrm{OP}=40 \%$; 8 - the same at $\mathrm{OP}=60 \%$

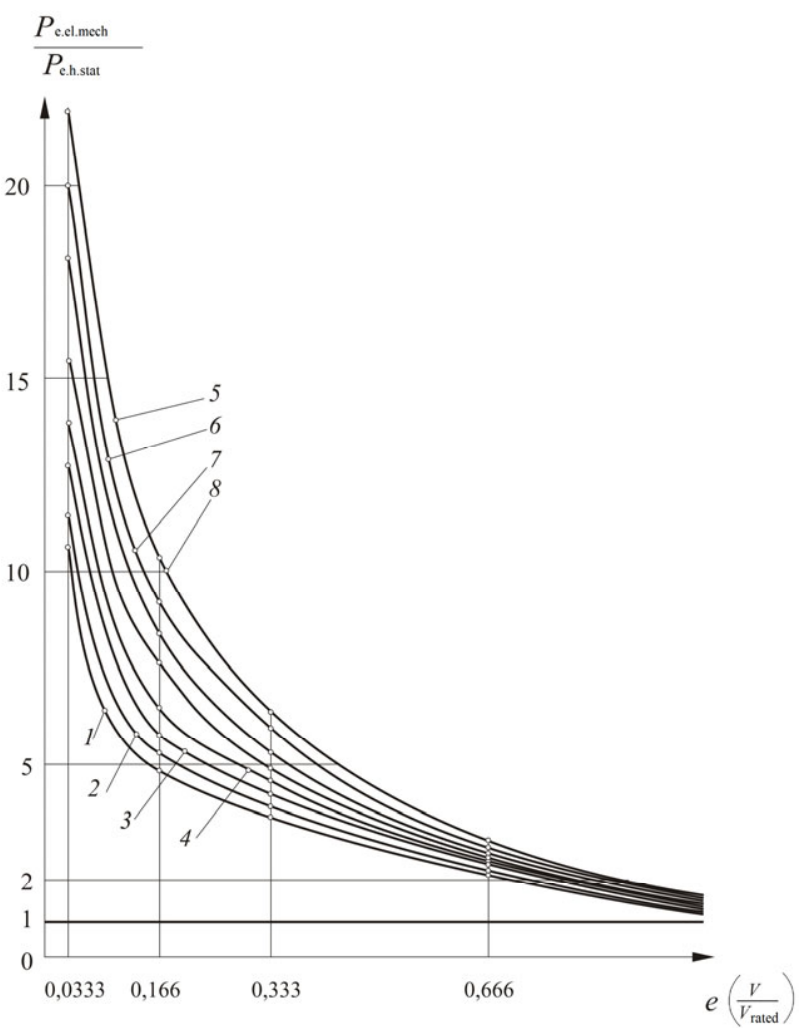

Fig. 6. The graphs of equivalent capacities relations $P_{\text {e.el }} / P_{\text {e.h }}=f(e)$ for electric and hydraulic drives.

On the grounds of the conducted research it can be stated that the rated capacity of hydraulic drive's electric motor when exploited in conditions of intensive acceleration, deceleration, and $\mathrm{OP} \%$ is less than that of electric drive. Similar conclusions can be reached by performing calculations by equivalent momentum.

\section{Conclusions}

There has been performed the comparison of rated and equivalent capacities and their ratios for electric and hydraulic drives of crane mechanisms depending on groups of operation conditions and operation period. The advantages of hydraulic drive's electric motor by equivalent capacity as compared with electric drive increase in the case when operation conditions are characterized by insignificant use of the drives' speed capacities. At small intensities of acceleration and deceleration and light operation conditions hydraulic drive by the rated capacity of electric motor is less effective than electric drive on account of low overload capacity of electric motors. The expounded conclusions determine advisable areas of using drives from the perspective of getting maximum advantages in terms of the equivalent and rated capacity.

\section{References}

1. Bratslavsky H.L. Hydrodynamic transmissions in construction and road machines. - Moscow: "Mashinostroyenie" (Machine-building) PH (1976).

2. Grigorov O.V., Krauze F., Macwardt G.G. Comparing efficiency factors and energy consumption in regulated hydrostatic and electromechanical drives Collected scientific articles of KhDPU. High technologies in machinebuilding, - Pp. $72-78$ (2000).

3. Petrov V.A. Hydrovolumetric transmissions of selfpropelled machines. - Moscow: "Mashinostroyenie" (Machine-building) PH (1988).

4. Kordak R. Der sekundärgeregelte hydrauliche Antrieb in mobilen Arbeitsgeräten $\mathrm{O}+\mathrm{P}$ „Ölhydraulik und Pneumatik“, - № 11-12 (1995).

5. Ruckganer N. Entwicklungstendenzen bei hydrostatischen Antrieben in mobilen Arbeitsmaschinen $\mathrm{O}+\mathrm{P}$ „Ölhydraulik und Pneumatik“, - № 11-12 (1993).

6. W. Backe. Technische Treds der Fluidec $\mathrm{O}+\mathrm{P}$ “Ölhydraulik und Pneumatik” № 11-12 (1995).

7. Grigorov O. KKD, vytraty enerhii u rehulovanomu hidrostatychnomu ta elektromekhanichnomu pryvodakh [Efficiency, energy consumption in controlled hydrostatic and electromechanical actuators]. Scientific, Technical and Production Journal „Lifting Structures. Special equipment". Odessa. №1 (184), - Pp. 14-17 (2018). [in Ukrainian]

8. Grigorov, O., Druzhynin, E., Anishchenko, G., Strizhak, M., Strizhak, V. Analysis of Various Approaches to Modeling of Dynamics of LiftingTransport Vehicles International Journal of Engineering \& Technology. № 7 (4.3) - Pp. 64-70 (2018)

9. Grigorov O., Anishchenko G., Petrenko N., Strizhak V., Turchin O., Radchenko V., Okun A. Polipshennia roboty kranovykh metalevykh 
konstruktsii shliakhom zastosuvannia hidropryvodu ta deiakykh inshykh rishen $v$ mekhanizmakh peresuvannia ta povorotu [Improving the performance of crane metal structures by applying hydraulic actuators and some other solutions in mechanisms of movement and rotation]. Lifting and Transport Engineering Scientific and Technical Journal. Odessa National Polytechnic University, № 2 - Pp. 4-14 (2019). [in Ukrainian]
10. Blanusa, B. New Trends in Efficiency Optimization of Induction Motor Drives New Trends in Technologies: Devices, Computer, Communication and Industrial Systems (2010).

11. Müller E., Engelmann J., Löffler T., Strauch J. Energieeffiziente Fabriken planen und betreiben [Plan and operate energy efficient factories] Berlin Heidelberg: Springer Verlag, (2009). 